University of Warwick institutional repository: http://go.warwick.ac.uk/wrap This paper is made available online in accordance with publisher policies. Please scroll down to view the document itself. Please refer to the repository record for this item and our policy information available from the repository home page for further information.

To see the final version of this paper please visit the publisher's website. Access to the published version may require a subscription.

Author(s): Kimberley A. Wade, Stefanie J. Sharman, Maryanne Garry, Amina Memon, Giuliana Mazzoni, Harald Merckelbach and Elizabeth F. Loftus

Article Title: False claims about false memory research

Year of publication: 2007

Link to published version:

http://dx.doi.org/10.1016/j.concog.2006.07.001

Publisher statement: None 


\title{
Running head: FALSE CLAIMS ABOUT FALSE MEMORY RESEARCH
}

False Claims About False Memory Research

Kimberley A. Wade ${ }^{1, *}$, Stefanie J. Sharman ${ }^{2}$, Maryanne Garry ${ }^{3}$, Amina Memon ${ }^{4}$, Giuliana Mazzoni $^{5}$, Harald Merckelbach ${ }^{6}$ \& Elizabeth F. Loftus ${ }^{7}$

\author{
${ }^{1}$ University of Warwick, United Kingdom \\ ${ }^{2}$ University of New South Wales, Australia \\ ${ }^{3}$ Victoria University of Wellington, New Zealand \\ ${ }^{4}$ University of Aberdeen, United Kingdom \\ ${ }^{5}$ University of Plymouth, United Kingdom \\ ${ }^{6}$ Maastricht University, The Netherlands \\ ${ }^{7}$ University of California, Irvine, United States of America
}

In Press Consciousness \& Cognition

*Correspondence concerning this article should be addressed to Kimberley Wade,

Department of Psychology, University of Warwick, Coventry, CV4 7AL, United Kingdom. Tel: +44 2476 575680; fax +44 2476 524225. Email address: K.A.Wade@warwick.ac.uk 


\begin{abstract}
Pezdek and Lam (in press) claim that the majority of research into false memories has been misguided. Specifically, they charge that false memory scientists have been [1] misusing the term "false memory," [2] relying on the wrong methodologies to study false memories, and [3] misapplying false memory research to real world situations. We review each of these claims and highlight the problems with them. We conclude that several types of false memory research have advanced our knowledge of autobiographical and recovered memories, and that future research will continue to make significant contributions to how we understand memory and memory errors.
\end{abstract}

Keywords: false memory; recovered memory; misinformation; DRM; false childhood memories; generalizing laboratory research 


\section{False Claims About False Memory Research}

Research into the puzzle of false memories has bloomed in the last decade. Contributions to the field have poured in from North America, Great Britain, New Zealand, Australia, Scandinavia, and other laboratories around the world. It's no wonder: the research area has enormous theoretical implications for how the mind works, as well as practical implications for legal, psychological, and other real world settings. However, Pezdek and Lam (in press; hereafter P \& L) claimed that the majority of research into false memories has been misguided. P \& L questioned the use of the term "false memory;" they criticized many of the methodologies used to study false memories, and they claimed that various paradigms could not advance our understanding of real world memory distortions. These criticisms would be cause for significant concern throughout the scientific community if they were wholly supported by data, previous scientific research, or solid theoretical reasoning. But they are not. In fact, we argue here that many of P \& L's claims are based on an incomplete coverage of the false memory literature or mistaken inferences about what the literature reveals.

\section{Summary of Pezdek and Lam (2005)}

\section{Aim and methodology}

P \& L sought to examine the methodologies that cognitive psychologists have been using over the previous decade to study false memories. They were particularly interested in identifying research involving the implantation of "entirely new events in memory" because "that was the intended use of the term false memory when it was coined" (p. 2). Their methodology involved using the Subject Heading field in PsycINFO to search for articles containing the term "false memory," and it resulted in the discovery of 188 
empirical papers published in cognitive journals between 1872 and 2004. Ten additional papers were added to their set because their search criteria failed to detect some frequently cited false memory research.

Next, P \& L categorized all 198 articles into one of six groups, according to the methodology used in each study. The six categories and the percentage of papers P \& L allocated to each group are listed in Table 1. The articles in each category are listed in Appendices A-F of P \& L. In an effort to avoid repetition, we describe the categories briefly here and provide some examples of articles that were allocated to each group.

Group 1 studies, in which researchers attempted to plant wholly false events into memory (e.g., Huffman, Crossman, \& Ceci, 1997; Porter, Yuille, \& Lehman, 1999), were of primary interest to P \& L. These implantation studies tended to use the method proposed by Loftus and Pickrell (1995) to create detailed and coherent memories for events that never happened. Loftus and Pickrell asked subjects to work at remembering descriptions of four childhood events. Three events were real and one was a fake; that event described the subject getting lost in a shopping mall at the age of five. Subjects tried to recall these events in three separate sessions over a few weeks, and by the final session, approximately $25 \%$ developed a complete or partial shopping-mall memory. False memory researchers have used variants of this technique to plant a variety of events in memory. However, the implantation method is extremely time consuming and laborious compared to other false memory techniques, so it is unsurprising that there are relatively few implantation studies.

Group 2 included studies that attempted to change memories for aspects of witnessed events; in other words, studies that used the misinformation effect (e.g., Frost, 2000; Hekkanen \& McEvoy, 2002). Typically, in misinformation studies, subjects watch a 
simulated crime such as a robbery (McCloskey \& Zaragoza, 1985). After a delay, subjects are exposed to postevent information (PEI) about the event. The PEI is accurate and nonspecific for some subjects ("the man had a tool"), but inaccurate and more specific for other subjects ("the man had a screwdriver"). Finally, subjects complete a memory test to determine the accuracy of their memory for the event. Studies like these show that relative to control subjects, misled subjects are more likely to report having seen the misleading details.

Group 3 included studies that used the Deese-Roediger-McDermott (DRM, Roediger \& McDermott, 1995) paradigm. Deese (1959) introduced this false memory technique, but Roediger and McDermott (1995) revived it and extended the findings in several directions. In a typical DRM study, subjects are exposed to lists of words that are semantically related to one unpresented target word. For example, Watson, Balota and Roediger (2003) presented subjects with lists of 12 semantically-related words (rye, loaf, crust...), phonologically-related words (bled, bride, braid...), or both semantically and phonologically related words (rye, bride, loaf...). Watson et al. then measured the intrusion of the critical unpresented word from which the lists were derived (bread). For the mixed semantic and phonologic lists, the level of false recall was quite high. The DRM procedure is one of the most popular and powerful methods used to study false memories, undoubtedly because numerous false memories can be produced in the memory report of individual subjects.

Group 4 included studies that used "general recognition memory" tasks. Studies in this group used recognition tests to examine false memories for objects, faces, compound words, narratives and other stimuli. For example, Koustaal et al. (2003, Expt 2) tested older 
and younger adults' memories for concrete and abstract objects. Older adults were more likely to falsely recognize concrete objects than younger adults, but the groups performed similarly on abstract objects.

Group 5 included studies that used source-monitoring tasks; that is, studies in which subjects had to determine the origin of their memories (e.g., Hicks \& Marsh, 2001; Poole \& Lindsay, 2002). Johnson and colleagues introduced the source-monitoring task to investigate how subjects distinguish between information derived from external sources (perceived events) and information derived from internal sources (imagined events) (Johnson \& Raye, 1981; Johnson, Hashtroudi, \& Lindsay, 1993). In one source-monitoring study, children aged 3-8 watched a character named Mr. Science perform science demonstrations (Poole \& Lindsay). Following the demonstrations, the children heard their parents describing events that Mr. Science never did. The children were then interviewed about their meeting with Mr. Science, but half received source-monitoring training before the interview. The source-monitoring training, which encouraged the children to consider the origins of their memories, reduced the number of false reports made by the 7 and 8 year-olds, but not the younger children.

Finally, Group 6 included some of the other techniques that scientists have used to study false memory phenomena (e.g., Assefi \& Garry, 2003; Merckelbach, Muris, Horselenberg, \& Stougie, 2000). One example is Lindsay, Wade, Read, and Hunter's (2004) investigation into naturally occurring false memories. Lindsay et al. asked adults whether they remembered or merely knew that certain likely and unlikely childhood events occurred. They found that $12 \%$ of adults had clear memories of seeing cigarette 
advertisements on television as children, even though television advertising of cigarettes was banned before the subjects were born.

\section{Results and Conclusions}

P \& L's literature search produced two key findings. First, $13.1 \%$ of the papers were classified as belonging to Group 1 - that is, studies describing the implantation of entirely new, yet false experiences. The second finding was that between 1994 and 2003, the number of articles with the term "false memory" in the subject heading increased dramatically, while the number of studies attempting to implant entire autobiographical events into memory remained steady at 2-3 per year.

Based on these two findings and a partial review of false memory research, P \& L drew three conclusions. First, they concluded, "few researchers have studied false memories as the term was originally intended - to specifically refer to planting memory for an entirely new event - and this pattern has remained relatively unchanged" (p. 5). Second, they concluded that there should be "one clear definition of false memory among cognitive researchers" (p. 5) because using the term false memory to describe a variety of memory distortions is "more likely to confuse than clarify the research" (p. 6). P \& L also offered a new taxonomy for categorizing false memories—false memories vs. flawed memories — an approach they say will prevent laypeople from over-generalizing research findings and "foster clearer communication between the clinical and experimental communities" (p. 6). Finally, P \& L concluded that laboratory based studies demonstrating "memory flaws," rather than "false memories," should not be generalized to "recovered" memories of longforgotten events, unless those studies have been shown to generalize to real world settings. 
At the same time P \& L were conducting their research, DePrince, Allard, Oh, and Freyd (2004) were conducting a similar review of the use of the term false memory in the psychological literature. Like P \& L, DePrince et al. reported that the majority of the empirical articles they sampled (70\% in their case) used the term false memory to refer to "errors in recall [or recognition] for details or parts of events." In this commentary, we focus predominantly on P \& L's paper, however, we refer to DePrince et al. when discussing issues that are common to both papers.

In sum, the main thrust of P \& L's thesis is that psychological scientists are misguided, and using the wrong techniques to study the wrong dependent measures. They present an unflattering review of the false memory literature, equating false memory scientists like us to a drunken man searching for his keys at the wrong end of an alley. Comedian Henny Youngman once said, "When I read about the evils of drinking, I gave up reading." Nonetheless, we read P \& L's paper, and carefully considered the logic and evidence behind their claims. In our paper, we present our analysis, and describe some of the false memory research that P \& L have failed to consider. We hope to give readers a more complete and accurate understanding of false memory research, and how it has advanced the understanding of memory construction and recovered memories.

\section{Pezdek and Lam's claims}

Claim 1. Few researchers have studied false memories as the term was originally intended

P \& L's research revealed that the term "false memory" was "first cited in the cognitive research literature in 1994" (p. 2). We were surprised to learn that the term "false memory" had such a brief history, so we conducted a search of our own. First, we conducted a PsycINFO search of the term "false memory" using the exact same criteria that 
P \& L used (i.e., using the Subject Heading field to search for empirical articles with the term "false memory"). In contrast to their search, ours yielded cognitive articles that were published prior to 1994 (i.e., Dittburner \& Persinger, 1993 and McCann \& Sheehan, 1987a). Although the discrepancy was not large (approximately 7 years) this finding led us to wonder whether P \& L's search criteria were too conservative to detect all of the cognitive research that used the term false memory. To examine this hypothesis, we carried out a PsycINFO search for the terms "false memory" or "false memories" using the Terms Anywhere function. Table 2 shows that our search produced 9 hits that were published before 1994, and they included empirical and review papers, a book chapter, plus a textbook. We wondered whether P \& L may have omitted other important papers from their review.

In addition to trying to trace its origin, $\mathrm{P} \& \mathrm{~L}$ examine the meaning of the term "false memories" itself, and say that it refers to "memory for an entirely new event, that is, an event or a specific episode of an event that was never experienced by an individual in his or her lifetime, but nonetheless, came to reside in the individual's memory" (p. 3; italics in original). They traced the term back to a talk that Elizabeth Loftus gave in 1992 at the American Psychological Association annual meeting, and to a paper Loftus published shortly thereafter in the American Psychologist titled "The reality of repressed memories" (Loftus, 1993). Pezdek must not remember attributing the term false memory to somebody else during a radio interview 13 years ago. In 1993, she claimed 'the term 'false memory' was coined by Pamela Freyd and members of the False Memory Syndrome Foundation" (McConnell, 1993). Readers can see a transcript of the interview at http://www.vuw.ac.nz/psyc/staff/maryanne-garry/index.aspx. 
Although Pezdek herself has at least two false memories of where the term "false memory" comes from, we are confident that it did not come from the radio debate with Freyd or from the Loftus article. Indeed, when we scoured the Loftus (1993) paper we did not see the definition that $\mathrm{P} \& \mathrm{~L}$ report. We did, however, find the following passage, which provides some insight into Loftus's use of the term:

Since the mid-1970s at least, investigations have been done into the creation of false memories through exposure to misinformation. Now, nearly two decades later, there are hundreds of studies to support a high degree of memory distortion... This growing body of research shows that new, postevent information often becomes incorporated into memory, supplementing and altering a person's recollection.... Understanding how we can become tricked by revised data about our past is central to understanding the hypothesis that suggestions from popular writings and therapy sessions can affect autobiographical recall. (Loftus, 1993, p.530).

It is clear from this passage that Loftus's definition of false memory included memories that were supplemented or altered by misleading postevent information. By contrast, P \& L's definition is restricted to memories that are created out of whole cloth, such as the type observed in memory implantation studies and in some misinformation experiments (e.g., Loftus, 1975; Loftus \& Pickrell, 1995).

Well, readers might wonder, even though P \& L had a false memory for the appearance of "false memory" in a 1993 article, perhaps their definition reflects how the term "false memory" is really being used in the scientific literature? The answer is no. In fact, it is common practice in the field of cognitive psychology to use the term "false memory" to describe a wide range of episodic memory distortions. To illustrate our point, consider the following quotes from peer-reviewed articles in the cognitive literature.

False-memory phenomena are so diverse: Some are characteristics of controlled laboratory tasks, others of everyday life; some occur for 
traumatic events with legal consequences, others for innocuous events; some are characteristic of one developmental level, others of another developmental level. (Brainerd \& Reyna, 2002, p. 164).

False memories manifest themselves in various forms (for a review, see Schacter, 1999), from changes in the context of a memory (e.g., believing you saw something that was imagined or believing you heard about an event on the television news rather than from a friend) to changes in the content of the memory itself (e.g., believing a criminal carried a gun rather than a knife), making it possible that there are several mechanisms by which these distortions occur. (Okado \& Stark, 2005).

Clearly, cognitive psychologists use the term false memory to describe a wide range of false memory phenomena. This is not to say that "false memory" is always an ideal term for describing the broad variety of memory illusions studied in our rapidly developing field. For one thing, the qualifier "false" may have negative connotations. Also, it is not always clear whether experimental procedures have increased people's confidence that false events happened in their pasts, created false beliefs that the events happened, or created false memories of the events (Mazzoni \& Kirsch, 2002; Smeets, Merckelbach, Horselenberg, \& Jelicic, 2005).

In short, we do not know where P \& L's definition of false memory came from. However, we do know that their definition does not reflect how the term is used by many scientists in the cognitive literature. In light of this finding, it does not seem reasonable to claim "few researchers have studied false memories as the term was originally intended" (p. $5)$.

Claim 2: There should be one clear definition of false memory among cognitive researchers

P \& L assert that memory researchers should reserve the use of the term "false memory" to describe situations in which people recall new and entire experiences that 
never occurred. They suggest that memory distortions involving relatively trivial or nonautobiographical events - such as those produced by the DRM paradigm or the misinformation procedure—should be called "memory flaws."

P \& L base their assertion on three points. First, they say that the term false memory was originally intended to mean a false recollection of an entirely new event. Second, they say that the mechanisms responsible for alterations in memory are different from those responsible for the creation of entirely new memories. DePrince et al. (2004) also argue that "The use of the same term for distinct phenomena assumes that they share cognitive and/or neuropsychological underpinnings in a theoretically meaningful way” (p. 210). Third, P \& L say that using the term false memory to represent a whole variety of memory errors might lead people to believe that all false memory research generalizes to recovered memories of abuse. Let us examine each of these points in turn.

P \& L's first point - that the term false memory referred to memory for an entirely new event - is based on a fallacy. As we noted earlier, P \& L's definition of false memory appears to be their own.

P \& L's second point— that the mechanisms underlying one type of false memory might not apply to other types of false memories - is not sufficiently supported. Indeed, to provide support for their point, P \& L cite one study by Pezdek and Roe (1997) in which children were led to believe an adult touched them in a non-threatening manner. Pezdek and Roe found that the children were more likely to report false memories of being touched in a specific way if they had been touched at an earlier session (in a slightly different way), than if they were not touched at all during the earlier session. Pezdek and Roe concluded, 
"it was relatively easier to suggestively change a memory than to suggestively plant or erase a memory" (italics in original, p. 102).

On the one hand, and as P \& L suggest, Pezdek and Roe's (1997) results could indicate that the mechanisms underlying altered memories are different from those underlying entirely new memories. On the other hand, at the time of writing our paper, Pezdek and Roe's results have not been replicated; attempts by Bruck, Ceci, and Francoeur (2000) as well as Krackow and Lynn (2003) have not been successful. The published literature may well underestimate the number of unsuccessful replications. A colleague described her attempts to replicate Pezdek and Roe's study; she abandoned the experiment partway through because a manipulation check showed that only $20 \%$ of the children in the "touch" condition recalled being touched immediately after the event occurred (I. Candel, personal communication, June 14, 2006). Together, these studies question the reliability of Pezdek and Roe's findings.

In addition to the failed attempts to replicate Pezdek and Roe's (1997) results, recent research by Jones and Powell (2005) suggests implanting a memory can be just as easy as changing an existing memory. Jones and Powell took 99 4-5 year olds and exposed half of them to fun activities, for example, hearing a story and interacting with a puppet. Two days later, the experimenters suggested to these children that a target, false activity was part of that experience (e.g., receiving a sticker). The other children, who were not exposed to the fun activities, were given the same suggestion but they were told that the false sticker event occurred on an unspecified day. Over the course of three interviews, the children who participated in the activities were just as likely to incorporate the suggestion into their existing memories as the other children were to create entirely new, but false 
memories. According to P\&L's logic, this finding would indicate that the mechanisms underlying changes in memory are similar to those underlying the creation of entirely new false memories.

In short, Pezdek and Roe's results have not been replicated making it difficult to judge the reliability of their findings. For now, we can say that partially different mechanisms might contribute to different levels of memory distortion, but further research is needed to clarify this issue. There is certainly not enough evidence to confidently state that different mechanisms underlie different memory illusions.

P \& L's final point is that restricting the term false memory to entirely new events will help thwart a tendency among some people who "might automatically assume that all cognitive research currently reported as false memory research generalizes to memories for childhood sexual abuse" (p. 6). Likewise, DePrince et al. (1994) state that "As scientists, we must be cautious that the language adopted to describe results does not lead to overgeneralization beyond the data" (p. 211). Here P \& L and DePrince et al. raise an important point: research findings are often taken out of context and applied to situations to which they are minimally relevant. We also agree that academics have a duty to try to prevent misapplications where possible.

But will a change in the way we use "false memory" stop laypeople from overgeneralizing false memory research? Of course, the question is an empirical one-but we suspect the answer is no. Scientists do not hold licenses to regulate the use of our terms. All one has to do to understand this fact is to consider how often laypeople actually mean shortterm memory when they use the term "short-term memory." The problem is not restricted to psychological science; it happens in all disciplines (When the Wicked Witch of the West 
screams "I'm melting! I'm melting!" chemists everywhere yell out, "No! You're dissolving!"). In addition to not being convinced by P \& L's argument to change the definition of false memory, below we show that the terminology they propose is neither workable nor effective.

\section{Distinguishing between "memory flaws" and "false memories."}

According to P \& L, the term "false memory" should be used to describe "research on memory for an entirely new event that did not occur, or research that has been demonstrated to generalize to memory for an entirely new event that did not occur" (p. 6). By contrast, the term "memory flaws" (or "false alarm") should be used for research "in which the original event is represented in memory but with one or more details retained incorrectly, or simply any false alarm on a recognition memory test" (p. 6). According to this taxonomy, the memory distortions demonstrated in implantation studies (Loftus \& Pickrell, 1995) are false memories, but the memory distortions demonstrated in misinformation studies (Loftus, Miller, \& Burns, 1978) or DRM studies (Roediger \& McDermott, 1995) are memory flaws.

At first glance, P \& L's distinction between memory flaws and false memories might seem workable. However, a closer look at this taxonomy shows that it is extremely difficult to use in some situations and it may even lead to nonsensical decisions about what is and what is not a false memory. To illustrate our point, we describe two situations in which we believe it is inappropriate to use P \& L's definition of false memories and memory flaws.

Situation 1: During a standard misinformation experiment, Bert is misled and reports seeing a "hammer" instead of a screwdriver at the memory test. Has Bert 
experienced a memory flaw or a false memory? In short, we do not know. On the one hand, if Bert encoded the screwdriver, then his memory distortion would be classified as a memory flaw. On the other hand, if Bert failed to encode the screwdriver during the initial "event" phase, then his memory distortion would be classified as a false memory. Although the outcome is the same in both cases, we cannot determine whether Bert has created a memory flaw or a false memory until we know whether he encoded the original item. In addition, P \& L say that false memories are memories of new events. Surely remembering a hammer that was never presented would constitute a new event? This point is particularly important because the issue of what constitutes an event has been debated for decades — and still is debated - within the event perception and memory literature (see Chemero, 2000; Dewey, 1896; Gibson, 1979; Roediger \& McDermott, 1996, Stoffregen, 2000; Tulving, 1983). Our hypothetical situation shows that subjects like Bert can produce the exact same response and still fall into both of P \& L's categories.

Situation 2. Ernie participates in a memory implantation study. He comes to remember taking a hot air balloon ride as a child, even though he has never been in a hot air balloon before. Has Ernie experienced a memory flaw or a false memory? We have no doubt that P \& L would say "false memory," because Ernie came to recall an entirely new event. However, there are two reasons why Ernie could also be categorized as having a memory flaw. First, according to P \& L, "Flaws in memory originate, for example, from post-event suggestion" (p. 6). We believe Ernie's memory distortion was created using a variant of post-event suggestion. For example, during his participation in the memory implantation study, Ernie attempted to recall events from his childhood (the original event). The experimenter suggested to him that taking a hot air balloon ride was a part of his 
eventful childhood (the post-event suggestion). By the end of the study period Ernie generated a vivid and detailed, yet false recollection of the target event (the test).

Second, according to P \& L, false memories are memories of "entirely new events." The problem with this definition is that false memories are rarely made up of entirely new details. Instead, they are often a fusion of imagined, real and suggested information (Lindsay \& Read, 1995; Read \& Lindsay, 1994; Wade, Garry, Read, \& Lindsay, 2002). Therefore it seems unhelpful to distinguish between false memories and memory flaws on the basis of how much new information they contain.

In sum, our Bert and Ernie scenarios illustrate just some of the problems with P \& L's criteria for distinguishing between memory flaws and false memories. We believe that analyzing the differences between various types of memory illusions and the processes that distinguish them is a worthy goal. However, the criteria that P \& L provide do not advance this goal; their criteria are not operationalized or based on sound theoretical reasoning. Claim 3: Most false memory research should not be generalized to real world settings (e.g., "recovered" memories)

This final claim centers around the concept of generalizability. Should we be generalizing research that shows changes in memory - such as DRM and misinformation experiments - to real world settings where people remember traumatic autobiographical experiences? According to $\mathrm{P} \& \mathrm{~L}$, it is "inappropriate to generalize directly from false memory research that did not involve planting entirely new events in memory to real world situations that do involve planting entirely new events in memory" (p. 7). They argue that laboratory based research should only be used to understand false memories in real world 
settings if that research has [a] created memories for an entirely new event, or [b] been shown to generalize to memories for entirely new events.

The issue of whether laboratory studies should be generalized to real world settings is, of course, worthy of attention and has been raised many times before (Anderson \& Bushman, 1997; Banaji \& Crowder, 1989; Locke, 1986; Mook, 1983). The take-home message in many of these scholarly contributions is that if the study has strict experimental control, that is, high internal validity, and addresses basic theoretical questions, then it makes little difference whether it is conducted in the laboratory or in the field, with ecologically interesting materials or with derived stimuli, or with college students or with middle-aged adults. In fact, demonstrating phenomena across a variety of settings strengthens the evidence for those phenomena. P \& L fail to acknowledge this point.

$\mathrm{P} \& \mathrm{~L}$ also ignore a substantial amount of evidence showing that a range of false memory research has advanced our understanding of false memories in the real world. When considering the value of "memory flaw" research, we must ask: Has this body of research helped to develop a generally accepted model of false memory construction? The answer is yes. For example, Loftus, Hyman and colleagues have suggested a general threepart model of memory construction (Hyman \& Kleinknecht, 1999; Hyman \& Loftus, 1998; see also Mazzoni, Loftus, \& Kirsch, 2001; Kihlstrom, 1996; and Pezdek, Finger, \& Hodge, 1997 who briefly discuss sections of this model). According to this model, people first must consider the event to be plausible. Second, they must believe that they were likely to have experienced the event. Third, they must make a source monitoring error; that is, they must mistake their thoughts, feelings and fantasies about the event as genuine memories. 
Research into what P \& L call "memory flaws" has been used to refine this threepart model and provide further evidence people must meet all three conditions to develop false memories. For example, Mazzoni and colleagues used a Life Events Inventory and pre-post test design to show that external suggestion can influence plausibility judgments and autobiographical beliefs about an event (Mazzoni et al., 2001; Mazzoni \& Memon, 2003) The convergent work of Garry and colleagues (Garry, Manning, Loftus, \& Sherman 1996; Garry, Sharman, Wade, Hunt, \& Smith, 2001), Goff and Roediger (1998), and Heaps and Nash (1999) has shown that instructions to imagine and repeatedly recall fictitious events influences autobiographical beliefs. Finally, the large body of literature on source monitoring has guided our understanding of the conditions in which people are likely to mistake false memories for genuine experiences (Johnson et al., 1993; Mitchell \& Johnson, 2000). These three lines of research are just some of the scientific studies that have shed light on the memory construction process. Without this research, false memory scientists would not have a general framework for understanding the memory construction that sometimes occurs in clinical settings.

Relatedly, more and more studies are showing that the effects found in false memory experiments, with highly derived stimuli such as words and pictures, can be extended to more ecological stimuli and different subject populations. For example, memory conjunction research shows that people often falsely recall or recognize a novel word (blackbird) that is made up of features from previously experienced words (blackmail and jailbird; Jones \& Jacoby, 2001; Reinitz, Lammers, \& Cochran, 1992). Odegard and Lampinen (2004) recently extended this effect and demonstrated conjunction errors for detailed, coherent, autobiographical events. Likewise, research using wordlists has shown 
that subjects often overestimate their prior forgetting of a target event (Arnold \& Lindsay, 2002; Schooler, Ambadar, \& Bendiksen, 1997). Geraerts et al. (in press) recently investigated this effect in people reporting either recovered or continuous memories of childhood abuse. They found that cuing subjects to think about an autobiographical event differently on two recall tests made them more likely to forget that they had recalled the event previously. This forgot-it-all-along effect was significantly stronger for participants reporting recovered memories. These examples clearly demonstrate that some memory illusions can occur across different stimuli and different subject groups.

There are many more studies in which false memory phenomena, initially found with derived stimuli, have been extended to more ecologically valid materials or populations (e.g., Gerrie, Belcher, \& Garry, 2006; Jones, Bartlett, \& Wade, 2006; McNally, Clancy, Barrett, \& Parker, 2005). Together, these studies strongly suggest that the results observed in what P \& L call "memory flaw" research can be used to hypothesize about autobiographical memory distortions. And let us not forget that psychological scientists study false memories because we have looked to the real world and have seen what happens. Psychological science tries to understand behavior out there by bringing it into the laboratory, not the other way around. This reductionism is, of course, typical for other scientific domains as well. For example, it would be nonsensical to argue that the research molecular biologists carry out on HIV is irrelevant to AIDS in real patients.

Finally, it appears that although P \& L apply the generalizability rule to other researchers, they are a bit less enthusiastic about applying it to themselves. In a recent paper that Pezdek co-authored, the researchers relied on word list research to back up their claim that the "cognitive and neurological mechanisms that may underlie the forgetting of 
abuse have been identified" (Freyd et al., 2005, p. 501). To support that claim, Freyd et al. cite research using the directed-forgetting paradigm (Anderson et al., 2004; DePrince \& Freyd, 2004). If P \& L genuinely believe that it is wrong to take research where people try to forget words and use it to help explain forgetting sexual abuse, then why are they doing just that?

\section{Conclusion}

We have tried to show that P \& L's claims were based upon premises that were either incorrect or unsubstantiated. We hope readers will be convinced that false memory scientists have been using suitable methodologies; and that changing the definition of the term false memory is unlikely prevent laypeople from over-generalizing false memory research. We have no doubt that future research will make significant contributions to how we understand the puzzles that memory presents us. 


\section{References}

Anderson, C. A., \& Bushman, B. J. (1997) External validity of "trivial" experiments: The case of laboratory aggression. Review of General Psychology, 1, 19-41.

Anderson, M. C., Oshsner, K. N., Kuhl, B., Cooper, J., Robertson, E., Gabrieli, S. W., Glover, G. H., Gabriel, J. D. E. (2004). Neural systems underlying the suppression of unwanted memories. Science, 303, 232-235.

Arnold, M. M., \& Lindsay, D. S. (2002). Remembering remembering. Journal of Experimental Psychology: Learning, Memory, and Cognition, 28, 521-529.

Assefi, S. L., \& Garry, M. (2003). Absolut ${ }^{\circledR}$ memory distortions: Alcohol placebos influence the misinformation effect. Psychological Science, 14, 77-80.

Banaji, M. R., \& Crowder, R. G. (1989). The bankruptcy of everyday memory. American Psychologist, 44, 1185-1193.

Barnier, A. J., \& McConkey, K. M. (1992). Reports of real and false memories: The relevance of hypnosis, hypnotizability, and context of memory test. Journal of Abnormal Psychology, 101, 521-527.

Benedek, E. P., \& Schetky, D. H. (1988). Problems in validating allegations of sexual abuse. Part 1: Factors affecting perception and recall of events. In S. Chess, A. Thomas, \& M. E. Hertzig (Eds.) (1989). Annual progress in child psychiatry and child development, 1988 (pp. 627-636). US: Brunner/Mazel, Inc.

Brainerd, C. J., \& Reyna, V. F. (2002). Fuzzy-trace theory and false memory. Current Directions in Psychological Science, 11, 164-169. 
Bruck, M., Ceci, S. J., \& Francoeur, E. (2000). Children's Use of Anatomically Detailed Dolls to Report Genital Touching in a Medical Examination: Developmental and Gender Comparisons. Journal of Experimental Psychology: Applied, 6, 74-83.

Chemero, A. (2000). What events are. Ecological Psychology, 12, 37-42.

Deese, J. (1959). On the prediction of occurrence of particular verbal intrusions in immediate recall. Journal of Experimental Psychology, 58, 17-22.

DePrince, A. P., Allard, C. B., Oh, H., \& Freyd, J. J. (2004). What's in a name for memory errors? Implications and ethical issues arising from the use of the term "false memory" for errors in memory for details. Ethics \& Behavior, 14, 201-233.

DePrince, A. P., \& Freyd, J. J. (2004). Forgetting trauma stimuli. Psychological Science, $15,488-492$.

Dewey, J. (1896). The reflex arc concept in psychology. Psychological Review, 3, 357-370.

Dittburner, T., \& Persinger, M. A. (1993). Intensity of amnesia during hypnosis is positively correlated with estimated prevalence of sexual abuse and alien abductions: Implications for the False Memory Syndrome. Perceptual and Motor Skills, 77, 895898.

Freyd, J. J., Putnam, F. W., Lyon, T. D., Becker-Blease, K. A., Cheit, R. E., Siegel, N. B., \& Pezdek, K. (2005). The science of child sexual abuse. Science, 308, 501.

Frost, P. (2000). The quality of false memory over time: Is memory for misinformation “remembered” or "known”? Psychonomic Bulletin \& Review, 7, 531-536. 
Garry, M., Manning, C. G., Loftus, E. F., \& Sherman, S. J. (1996). Imagination inflation: Imagining a childhood event inflates confidence that it occurred. Psychonomic Bulletin \& Review, 3, 208-214.

Garry, M., Sharman, S. J., Wade, K. A., Hunt, M. J., \& Smith, P. J. (2001). Imagination inflation is a fact, not an artifact: A reply to Pezdek and Eddy. Memory \& Cognition, 29, 719-729.

Gerrie, M.P., Belcher, L., \& Garry, M. (2006). Systematic eyewitness false memories occur in the absence of external suggestion. Applied Cognitive Psychology, 20, 689-696.

Geraerts, E., Arnold, M. M., Lindsay, D. S., Merckelbach, H., Jelicic, M., \& Hauer, B. (in press). Forgetting of prior remembering in persons reporting recovered memories of childhood sexual abuse. Psychological Science.

Gibson, J. J. (1979). The ecological approach to visual perception. Boston, Houghton Mifflin.

Goff, L. M., \& Roediger, H. L. (1998). Imagination inflation for action events: Repeated imaginings lead to illusory recollections. Memory \& Cognition, 26, 20-33.

Gregg, V. H. (1987). Hypnotic pseudomemory: Continuing issues. British Journal of Experimental and Clinical Hypnosis, 4, 109-111.

Gutheil, T. G. (1993). True or false memories of sexual abuse? A forensic psychiatric view. Psychiatric Annals, 23, 527-531.

Heaps, C., \& Nash, M. (1999). Individual differences in imagination inflation. Psychonomic Bulletin \& Review, 6, 313 - 318. 
Hekkanen, S. T., \& McEvoy, C. (2002). False memories and source-monitoring problems: Criterion differences. Applied Cognitive Psychology, 16, 73-85.

Hicks, J. L., \& Marsh, R. L. (2001). Attempts to reduce the incidence of false recall with source monitoring. Journal of Experimental Psychology: Learning, Memory, and Cognition, 25, 1195-1209.

Huffman, M. L., Crossman, A. M., \& Ceci, S. J. (1997). “Are false memories permanent?”: An investigation of the long-term effects of source misattributions. Consciousness \& Cognition, 6, 482-490.

Hyman, I. E., Jr., \& Kleinknecht, E. E. (1999). False childhood memories. In L. M. Williams \& V. L. Banyard (Eds.). Trauma and memory (pp. 178-188). Thousand Oaks, CA, USA: Sage Publications, Inc.

Hyman, I.E. Jr \& Loftus, E.F. (1998) Errors in autobiographical memory. Clinical Psychology Review, 18, 933-947.

Jacoby, L. L., \& Whitehouse, K. (1989). An illusion of memory: False recognition influenced by unconscious perception. Journal of Experimental Psychology: General, $118,126-135$.

Johnson, M. K., Hashtroudi, S., \& Lindsay, D. S. (1993). Source monitoring. Psychological Bulletin, 114, 3-28.

Johnson, M. K., \& Raye, C. L. (1981). Reality monitoring, Psychological Review, 88, 6785. 
Jones, T. C., Bartlett, J. C., \& Wade, K. A. (2006). Nonverbal conjunction errors in recognition memory: Support for familiarity but not for feature bundling, Journal of Memory and Language, 55, 138-155.

Jones, T. C., \& Jacoby, L. L. (2001). Feature and conjunction errors in recognition memory: Evidence for dual-process theory. Journal of Memory and Language, 45, 82102.

Jones, C. \& Powell, M. B. (2005). The effect of event context on children's recall of nonexperienced events across multiple interviews. Legal and Criminological Psychology, 10, 83-101.

Kihlstrom, J. F. (1996). The trauma-memory argument and recovered memory therapy. In K. Pezdek \& W. P. Banks (Eds.), The recovered memory/false memory debate. (pp. 297-311). San Diego: Academic Press.

Koustaal, W., Reddy, C., Jackson, E. M., Prince, S., Cendan, D. L., \& Schacter, D. L. (2003). False recognition of abstract versus common objects in older and younger adults: Testing the semantic categorization account. Journal of Experimental Psychology: Learning, Memory, and Cognition, 29, 499-510.

Krackow, E., \& Lynn, S. J. (2003). Is There Touch in the Game of Twister $®$ ? The Effects of Innocuous Touch and Suggestive Questions on Children's Eyewitness Memory. Law and Human Behavior, 27, 589-604

Lindsay, D. S., \& Read, J. D. (1995). "Memory work" and recovered memories of childhood sexual abuse: Scientific evidence and public, professional, and personal issues. Psychology, Public Policy, and the Law, 1, 846-908. 
Lindsay, D. S., Wade, K. A., Read, J. D., \& Hunter, M. A. (2004). Adults' memories of childhood: Affect, knowing and remembering. Memory, 12, 27-43.

Locke E. A. (1986). Generalizing from laboratory to field settings. MA: Lexington Books.

Loftus, E.F. (1975). Leading questions and the eyewitness report. Cognitive Psychology, 7, $560-572$.

Loftus, E. F. (1993). The reality of repressed memories. American Psychologist, 48, 518537.

Loftus, E.F., Miller, D.G., \& Burns, H.J. (1978). Semantic integration of verbal information into a visual memory. Journal of Experimental Psychology: Human Learning and Memory, 4, 19-31.

Loftus, E. F., \& Pickrell, J. E. (1995). The formation of false memories. Psychiatric Annals, 25, 720-725.

Mazzoni, G., A. L., \& Kirsch, I. (2002). Autobiographical memories and beliefs: A preliminary metacognitive model. In T. J. Perfect \& B. L. Schwartz (Eds.). Applied metacognition. (pp. 121-145). NY: Cambridge University Press.

Mazzoni, G. A. L., Loftus, E. F., \& Kirsch, I. (2001). Changing beliefs about implausible autobiographical events: A little plausibility goes a long way. Journal of Experimental Psychology: Applied, 7, 51-59.

Mazzoni, G. A. L., \& Memon, A. (2003). Imagination can create false autobiographical memories. Psychological Science, 14, 186-188. 
McCann, T. E., \& Sheehan, P. W. (1987a). The breaching of pseudomemory under hypnotic instruction: Implications for original memory retrieval. British Journal of Experimental and Clinical Hypnosis, 4, 101-108.

McCann, T. E., \& Sheehan, P. W. (1987b). Pseudomemory reports and their variable explanations. British Journal of Experimental and Clinical Hypnosis, 4, 112-114.

McCloskey, M., \& Zaragoza, M. (1985). Misleading postevent information and memory for events: Arguments and evidence against memory impairment hypotheses. Journal of Experimental Psychology: General, 114, 1-16.

McConnell, M. (Producer/Host). (1993, December 6). The Midday Show [Radio broadcast]. Cincinnati: WLW-AM (700)

McNally, R. J., Clancy, S. A., Barrett, H. M., \& Parker, H. A. (2005). Reality monitoring in adults reporting repressed, recovered, or continuous memories of childhood sexual abuse. Journal of Abnormal Psychology, 114, 147-152.

Merckelbach, H., Muris, P., Horselenberg, R., \& Stougie, S. (2000). Dissociative experiences, response bias, and fantasy proneness in college students. Personality \& Individual Differences, 28, 49-58.

Mitchell, K. J., \& Johnson, M. K. (2000). Source monitoring: Attributing mental experiences. In E. Tulving, \& F. I. M. Craik (Eds.), The Oxford Handbook of Memory (pp. 179-195), NY: Oxford University Press.

Mook, D. (1983). In defense of external invalidity. American Psychologist, 38, 379-387.

Odegard, T. N., \& Lampinen, J. M. (2004). Memory conjunction errors for autobiographical events: More than just familiarity. Memory, 12, 288-300. 
Okado, Y., \& Stark, C. E. L. (2005). Neural activity during encoding predicts false memories created by misinformation. Learning and Memory, 12, 3-11.

Pezdek, K. \& Lam, S. (in press). What research paradigms have cognitive psychologists used to study "False memory," and what are the implications of these choices? Consciousness \& Cognition.

Pezdek, K., Finger, K., \& Hodge, D. (1997). Planting false childhood memories: The role of event plausibility. Psychological Science, 8, 437-441.

Pezdek, K., \& Roe, C. (1997). The suggestibility of children's memory for being touched: Planting, erasing, and changing memories. Law and Human Behavior, 21, 95-106.

Poole, D. A., \& Lindsay, D. S. (2002). Children's eyewitness reports after exposure to misinformation from parents. Journal of Experimental Psychology: Applied, 7, 27-50.

Porter, S., Yuille, J. C., \& Lehman, D. R. (1999). The nature of real, implanted and fabricated memories for emotional childhood events: Implications for the false memory debate. Law \& Human Behavior, 23, 517-538.

Read, J. D., \& Lindsay, D. S. (1994). Moving toward a middle ground on the 'false memory debate': Reply to commentaries on Lindsay and Read. Applied Cognitive Psychology, 8, 407-435.

Reinitz, M. T., Lammers, W. J., \& Cochran, B. P. (1992). Memory-conjunction errors: Miscombination of stored stimulus features can produce illusions of memory. Memory \& Cognition, 20, 1-11. 
Roediger, H. L., \& McDermott, K. B. (1995). Creating false memories. Remembering words not presented in lists. Journal of Experimental Psychology: Learning, Memory, \& Cognition, 21, 803-814.

Roediger, H. L., \& McDermott, K. B. (1996). False perceptions of false memories. Journal of Experimental Psychology: Learning, Memory, and Cognition, 22, 814-816.

Schooler, J. W., Ambadar, Z., Bendiksen, M. (1997). A cognitive corroborative case study approach for investigation discovered memories of sexual abuse. In J. D. Read \& D. S. Lindsay (Eds.), Recollections of Trauma: Scientific Research and Clinical Practices (pp. 379-388). New York: Plenum.

Smeets, T., Merckelbach, H., Horselenberg, R., \& Jelicic, M. (2005). Trying to recollect past events: Confidence, beliefs, and memories. Clinical Psychology Review, 25, 917934.

Stoffregen, T. A., (2000). Affordances and events. Ecological Psychology, 12, 1-28.

Tulving, E. (1983). Elements of episodic memory. New York: Oxford University Press.

Wade, K. A., Garry, M., Read, J. D., \& Lindsay, D. S. (2002). A picture is worth a thousand lies: Using false photographs to create false childhood memories. Psychonomic Bulletin \& Review, 9, 597-603.

Watson, J. G. (1993). Dealing with the problem of "false memory" in clinic and court. Journal of Psychiatry and Law, 21, 297-317.

Watson, J. M., Balota, D. A., \& Roediger, H. L. (2003). Creating false memories with hybrid lists of semantic and phonological associates: Over-additive false memories produced by converging associative networks. Journal of Memory and Language, 49, 95-118. 
False claims 31

Yapko, M. D. (1990). Trancework: An introduction to the practice of clinical hypnosis ( $2^{\text {nd }}$ ed.). US: Brunner/Mazel. 


\section{Author Note}

We thank Alan Scoboria, Ingrid Candel, and James Ost for their excellent suggestions. 
False claims 33

Table 1.

Pezdek and Lam's (in press) six categories of "false memory" research and the percentage of studies classified according to each type of task.

Group 1: Whole new event planted

Group 2: New or changed details planted

Group 3: DRM

Group 4: General recognition memory

Group 5: Source monitoring

Group 6: Other
13.1

16.2

41.4

15.7

6.1

7.6

TOTAL 100 
Table 2 .

Articles, books, and chapters that were published before 1994 and contain the term "false memory" or "false memories."

Author (Date)

Title

Source

(Publication Type)

Dittburner, T. L., \& Persinger, M. A. (1993) (empirical)

Watson, J. G. (1993) (review)

Gutheil, T. G. (1993) (review)

Barnier, A. J., \& McConkey, K. M. (1992) (empirical)

Yapko, M. D.(1990) (textbook)

Jacoby, L. L., \& Whitehouse, K. (1989) (empirical)

Benedek, E. P., \& Schetky, D. H. (1989) (book chapter)
Intensity of amnesia during hypnosis is positively correlated with estimated prevalence of sexual abuse and alien abductions: Implications for the False Memory Syndrome.

Dealing with the problem of "false memory" in clinic and court

True or false memories of sexual abuse? A forensic psychiatric view.

Reports of real and false memories: Journal of The relevance of hypnosis, hypnotizability, and context of memory test.

Psychology

Psychiatry and

Law

Psychiatric Annals

Perceptual and

Motor Skills

Trancework: An introduction to the US: practice of clinical hypnosis (2nd Brunner/Mazel, ed.). Inc,

An illusion of memory: False Journal of recognition influenced by Experimental unconscious perception. Psychology:

General

Problems in validating allegations Annual Progress in of sexual abuse: I. Factors affecting Child Psychiatry perception and recall of events.

and Child Development. US: 
Brunner / Mazel,

Inc

McCann, T. E., \& Sheehan, P. W. (1987a) (empirical)

McCann, T. E., \& Sheehan, P. W. (1987b) (comment)

Gregg, V. H. (1987) (comment)
The breaching of pseudomemory under hypnotic instruction: Implications for original memory retrieval.

Pseudomemory reports and their variable explanations.

Hypnotic pseudomemory:

Continuing issues.
British Journal of Experimental and Clinical Hypnosis

British Journal of Experimental and Clinical Hypnosis

British Journal of Experimental and Clinical Hypnosis 